\title{
Orthokeratology: clinical utility and patient perspectives
}

This article was published in the following Dove Press journal:

Clinical Optometry

7 February 2017

Number of times this article has been viewed

\section{Jessie Charm}

Sight Enhancement Center, Hong Kong Special Administrative Region
Correspondence: Jessie Charm

Sight Enhancement Center, Unit I204, Kowloon Building, 555 Nathan Road,

Hong Kong Special Administrative Region

$\mathrm{Tel}+85223021898$

Email jessie@eyecare.com.hk
Abstract: Orthokeratology (ortho-k) is a special rigid contact lens worn at night to achieve myopic reduction and control. This review provides an overview on prescribing ortho-k, including clinical consideration on patient aspect and lens design; its clinical outcomes; and clinical efficacy and safety. Patient satisfaction was summarized. In order to achieve long-term healthy ortho-k treatment, it requires both patient and practitioners' care and rapport to maintain good ocular health and lens conditions.

Keywords: orthokeratology, efficacy, patient satisfaction, myopic reduction, myopic control

\section{Introduction}

There is an increasing clinical interest in myopic progression in children. In addition, scientific interest in various myopic control methods has also been strong. In recent years, orthokeratology (ortho-k) treatment has become a clinically acceptable and effective method. The treatment involves a special curved lens fitted to mold the corneal contour in order to achieve myopic reduction and has also resulted in myopic retardation. Clinicians are required to refine the technique and remain up to date in this field.

This review provides an overview of ortho-k, clinical considerations, and outcomes for different forms of ametropia, as well as clinical efficacy and safety. Ortho-k treatment is long term and requires patient care and rapport to monitor ocular health and lens conditions.

\section{Overview of ortho-k}

An initial study on corneal reshaping, or ortho-k, was reported in the $1950 \mathrm{~s}$, but the clinical term "ortho-k" was not introduced until 1962. Kerns carried out the first largescale clinical studies to investigate the safety and efficacy of ortho-k. ${ }^{1-8}$ However, he admitted that the change in refractive errors was unpredictable. Initially, ortho-k was a corneal molding procedure that involved wearing a rigid gas permeable lens..$^{9-12}$ The myopic reduction was $\sim 1.00 \mathrm{D},{ }^{1,2,7,10,13}$ but the progress of myopic reduction was slow, and the procedures involved a series of lenses with different back optic zone radii (BOZR). A breakthrough in ortho-k was achieved when high gas permeable materials and computerized corneal topographers were introduced. ${ }^{14,15}$ The lens was modified for "accelerated ortho-k," which achieved faster responses and up to $5.00 \mathrm{D}$ in myopic reduction. This meant that the reduction effect can be achieved within the first month of lens wear. ${ }^{12,16,17}$ 
A conventional rigid gas permeable lens is a bicurved lens that has a BOZR and a peripheral curve. A basic standard ortho-k lens, or reverse geometry lens, has three curves, from center to periphery: a BOZR, a reverse curve, and a peripheral curve. The reverse curve assists the corneal molding effect. In order to improve lens centration, the lens is further modified to multicurve design. An alignment curve is introduced and incorporated between the reverse curve and the peripheral curve. This alignment curve may also be divided into two curves (AC1 and $\mathrm{AC} 2$ ) to form a five-zone lens.

This combination of different curves controls the lens sag height to create a molding effect. Adjusting the BOZR alone does not affect the lens fitting. Induced corneal changes are dependent on the combination of the BOZR and the used reverse curve, that is, overall lens sag.

In closed eye condition, the tear layer under the lens sag creates both a positive force and a negative force on the cornea to change the efficacy of treatment. The positive force is exerted to flatten the central cornea, and the negative force is extracted against the mid-peripheral cornea. With these two forces, the epithelial cells are driven from center to mid-peripheral cornea, resulting in a negative epithelial lenticule to reduce the myopia. The zone of the reverse curves is a relief area for tissue redistribution. ${ }^{12}$

The lens centration is determined by using the alignment curve where the lens is landed on the peripheral cornea. The tear exchange is maintained by adequate edge lift under the peripheral curve. ${ }^{12}$

In contact lens assessment with the application of fluorescein, an ortho-k lens shows bearing at the corneal apex because the thickness of tear layer is $\sim 5 \mu \mathrm{m} .{ }^{18}$ Bearing is also found at the alignment curve because no tears exist when the alignment curve aligns the peripheral cornea. The thickness of tear layer is maximal at the BOZR/reverse curve junction. Any tear layer thickness $>20 \mu \mathrm{m}$ is visible in green when fluorescein is applied. ${ }^{18}$

\section{Clinical considerations}

Ortho-k was originally prescribed for adults to reduce myopia. As a myopic control effect was found in many studies, it is now mainly prescribed for children. In order to enhance the efficacy and safety of ortho-k, practitioners should consider the following factors before prescribing the lens.

1. Basic patient criteria

Many studies have been conducted with children at the age of 7 years, ${ }^{16,19-26}$ and some schools/colleges of optometry have reported age recommendations for myopia treatment with ortho-k in children as young as 5-6 years. ${ }^{27}$ However, ortho-k treatment depends more on the maturity level of the patient rather than on age. In addition to patient maturity level, practitioners should also consider the level of parent participation. ${ }^{27}$

Parents should help their children in monitoring lens insertion and removal, as well as lens usage and care. ${ }^{28}$ Incomplete instructions or deviation from the procedures will lead to lens contamination. Moreover, parental support applies also to aftercare visits, in which practitioners will evaluate ocular health and refractive change. ${ }^{29}$ Both the parties will discuss and agree on a solution if any abnormality is found.

Cho et al recommended that informed consent should be obtained from the patient, his/her parents, and practitioners. ${ }^{29}$ Both the patient and his/her parents should be informed about potential effects, patient alternatives, and the importance of compliance. Practitioners should provide an emergency contact number for any serious issues. The three parties share equal responsibility for good, long-term clinical care under ortho-k treatment. As with any kind of medical treatment, a good rapport is also required.

2. Baseline refraction errors

Most studies reported patients with mild-to-moderate myopia ( $-0.75 \mathrm{D}$ to $-5.00 \mathrm{D})$ and low astigmatism (up to $1.50 \mathrm{D})$ as good candidates for ortho-k treatment. This is because $\sim 90 \%$ of myopia and $50 \%$ of astigmatism have been corrected under these conditions. ${ }^{16,19-26,30,31}$ Several studies have reported that toric ortho-k could reduce astigmatism up to $-3.00 \mathrm{D},{ }^{21,32-34}$ and scattered cases have reported full correction for high myopia (myopia $>6.00$ D). ${ }^{24}$ However, these studies included no details on ocular health after lens wear. Clinically, practitioners may use a series of ortho-k lenses to correct high myopia.

3. Corneal profile

Keratometers can measure only up to $3 \mathrm{~mm}$ and cannot reflect the true corneal profile after ortho-k treatment. Therefore, corneal topography is crucial in prescribing ortho-k because it helps in screening out unqualified patients who show a decentered corneal apex, keratoconus, or irregular corneas. ${ }^{35-37}$ Topography should be accurate and repeatable $e^{35,36}$ and should provide various maps including axial (for corneal power), tangential (for corneal shape), refractive, and curvature maps in different adjustable scales. ${ }^{37}$ Practitioners must measure the corneal profile in every aftercare visit to monitor any subtle changes in corneal curvature. 
During the initial assessment, both the axial and tangential power maps are used to check for any corneal asymmetry or abnormality. Once ortho-k is fitted, the cornea will be molded, and the molding response is always compared with the baseline topography. The subtraction map function is essential to evaluate topographical changes and the lens-corneal relationship. The common ortho-k responses include bull's eye, central island (central curvature steepens than periphery), frowny face (lens decenters down), and smiley face (lens decenters up). With any undesirable responses, practitioners should amend the lens fitting accordingly.

Apart from screening out unsuitable patients, corneal astigmatism is judged by the corneal profile. Baseline corneal astigmatism was suggested to be $<1.50 \mathrm{D}$ in the previous studies ${ }^{30}$ until toric ortho-k was introduced to correct up to $-3.00 \mathrm{D}$ astigmatism. ${ }^{32,33,38,39}$ Clinically, good centration and a reduction effect are found when the refraction astigmatism is in line with the corneal astigmatism, in terms of diopter and axis, to prevent residual astigmatism. Any against-the-rule or limbus-to-limbus corneal astigmatism may affect lens centration.

4. Horizontal visual iris diameter (HVID) and pupil diameter HVID is used to determine the lens diameters and can be measured by a ruler, by adjustable slit size on a slit lamp, or based on a corneal topographical map. Some lens manufacturers suggest that the lens size should cover $95 \%$ of the HVID at most as lateral decentration may occur in a smaller lens.

Pupil diameter should be measured under both photopic and scotopic environments. If the treatment zone is smaller than the pupil size, then the patients may experience flare and glare, especially in dim light. According to Munnerlyn's formula, the more the myopic reduction using ortho-k, the smaller the treatment zone size. ${ }^{40}$ van der Worp and Ruston suggested that the treatment zone should be $3.5 \mathrm{~mm}$ with changes in corneal thickness of $20 \mu \mathrm{m}$ and myopic reduction of 4.90 D. ${ }^{41}$

5. Eyelid features

Loose eyelids may not exert enough force, whereas tight eyelids may exert too much force on the ortho-k lens in closed eye condition. As this is difficult to measure clinically, an overnight trial is essential to assess topographical responses. $^{37}$

\section{Lens design consideration}

A spherical or toric ortho-k lens is prescribed based on corneal profile and refractive errors. A spherical lens can only correct slight astigmatism. ${ }^{16,30}$ When corneal astigmatism is $\geq 1.50 \mathrm{D}$, fitting a spherical lens leads to induced astigmatism or lens decentration and results in poor vision. A toric lens is suggested under these conditions. ${ }^{21,34,39}$ Only the reverse, alignment, and/or peripheral curves are toric to enhance the centration of lens fit.

Practitioners can use computer software to generate a new lens or select an initial lens from a set of trial lenses. ${ }^{21,34}$ Some computer software uses patient information including spectacle prescription, HVID, and corneal sagittal height data to determine the ortho-k lens parameter. Practitioners may be allowed to adjust the lens parameters by using the software to estimate the lens fit. Some manufacturers provide a diagnostic lens set so that practitioners can evaluate fit in-office. The first lens from the diagnostic lens set can be selected according to the flat $\mathrm{K}$, eccentricity, and/or manufacturer's fitting guide.

When practitioners receive the diagnostic lenses, both static and dynamic assessments of contact lens fitting are suggested to eliminate major size discrepancies. However, fluorescence can only be seen with the naked eye if the tear layer is $>20 \mu \mathrm{m},{ }^{18,42}$ and therefore, it is difficult to assess lens performance in-office. Overnight topographical response is the most valid procedure for evaluating lens fit. It determines the centration of the lens and the physiological response to the treatment while also monitoring changes, assisting with problem-solving, and refining the lens fit.

\section{Ortho-k effect on different forms of ametropia Myopia}

A myopic ortho-k effect results from a central corneal flattening and a paracentral corneal steepening. Studies have indicated that $\sim 80 \%$ reduction would be resulted if the baseline myopia is $<5.00 \mathrm{D}$. The most significant reduction occurs after the first overnight wear $(\sim 60 \%)$ and keeps down steady for the next week. The reduction rate levels off after 1 month of lens wear. ${ }^{19,21,22,24-26,43}$

\section{Hyperopia}

A hyperopic ortho-k effect results from a central corneal steepening and a paracentral corneal flattening. Several short-term pilot studies have shown hyperopic reduction after $1 \mathrm{~h}$ and an increased effect with longer lens wear. According to Gifford et al, "A good (hyperopic) lens fit must exhibit central clearance over the optical zone and progress to midperipheral touch while maintaining adequate edge lift." ${ }^{44,45}$ However, there are limited studies on the corneal effect and clinical assessment on hyperopic ortho-k. 


\section{Astigmatism}

Astigmatism correction has been reported at $50 \%$ of withthe-rule astigmatism when the corneal cylinder is $<1.50 \mathrm{D}$. However, additional case studies have shown more promising results by using toric ortho-k to correct astigmatism..$^{21,32-34,38}$ Chen et al reported $80 \%$ reduction on astigmatism in 6 months by using toric ortho-k. ${ }^{21}$ In their study, the astigmatism was decreased from $-1.86 \pm 0.64 \mathrm{D}$ to $-0.37 \pm 0.39$ $\mathrm{D}$ in 6 months. The reduction was maintained throughout a 2-year study.

\section{Corneal thickness changes}

In myopia reduction, previous studies have shown a change in corneal thickness at the epithelium (thinning at the central epithelium, but thickening at the mid-peripheral epithelium) ${ }^{46-48}$ In hyperopic ortho-k, the central epithelium remains the same, whereas the mid-peripheral epithelium was thinned by $15 \%$ after $8 \mathrm{~h}$ of lens wear. However, more detailed studies are required to investigate the progress of refractive changes and corneal thickness changes in the hyperopic ortho-k effect. ${ }^{45,49}$

\section{Daytime regression in myopic ortho-k effect}

Mountford found that the regression of refractive errors was $\sim 0.50-0.75 \mathrm{D}$ after $8 \mathrm{~h}$ of lens removal in Caucasians, ${ }^{50}$ but he did not find a correlation between refractive change and regression. Gardiner et al further traced the refractive errors changed after lens removal. ${ }^{51}$ The subjects in their study wore ortho-k for $6 \mathrm{~h}$. They traced the refractive changes in every $5 \mathrm{~h}$. The regressions were $0.39 \mathrm{D}$ and $0.60 \mathrm{D}$ after $6 \mathrm{~h}$ and $15 \mathrm{~h}$ of lens removal, respectively. They suggested a correlation between baseline myopia and the total regression. Chan et al reported that the daytime regression in refractive errors was insignificant in Chinese, and they did not find the correlation. ${ }^{16}$ They commented that the regression was unpredictable, which may not be reflected by objective refractive and topographic responses.

\section{Clinical efficacy of ortho-k}

Myopia increases with the elongation of axial length. Hence, a correlation between the axial elongation and visual feedback is suggested. A normal cornea is steepened centrally and gradually flattens to the periphery. Light will be focused at the macula, and it is behind the retina at the periphery (peripheral hyperopia). Studies found that the relative periphery hyperopia is greater in myopes than in emmetropes or hyperopes. ${ }^{52-56}$ It was proposed that the peripheral hyperopic defocus may promote axial myopia. ${ }^{52-56}$ The corneal shape was changed after ortho-k treatment. The central cornea flattening and midperiphery steepening reduce the relative peripheral hyperopia in myopic eyes. This is considered a potent myopia-inhibiting indicator. ${ }^{57-60}$ Recent randomized myopic control studies have indicated that ortho-k retards myopic progression in low myopes, high myopes, and astigmatic patients (Figure 1). The retardation rate was comparable to those using atropine, but it was higher than in those wearing special soft contact lenses and progressive/bifocal glasses. ${ }^{21-25,43,61-75}$

\section{Ortho-k on high myopes}

Most commercially available ortho-k lenses and those used in published reports are limited to moderate myopes $(\sim 5.00 \mathrm{D})$ only. Several reports were suggested that visual acuities were good on high myopes after ortho-k treatment, ${ }^{76}$ and they did not present details on ocular health condition after lens wear.

Clinically, when the lens target is increased to $\geq 5.00 \mathrm{D}$, significant corneal staining and lens decentration are found..$^{31,77}$ A cautious ortho-k treatment on high myopes was introduced. ${ }^{22} \mathrm{~A}$ certain amount of myopia was reduced by using ortho-k (partial reduction [PR]), and the remaining refractive errors were corrected by spectacles. In a high myopia study, ${ }^{22}$ the high myopes (myopia of $\geq 5.75$ ) were randomly enrolled in study (PR with ortho-k and spectacles) and control (correction with spectacles only) groups. In the study group, ortho-k lens was fitted to reduce $4.00 \mathrm{D}$ myopia, whereas a pair of single-vision spectacles was prescribed to correct any remaining refractive errors. In the control group, only a pair of single-vision spectacles was prescribed. The myopic progression and axial lengths were monitored for 2 years. The axial lengths were $0.19 \pm 0.21 \mathrm{~mm}$ and $0.51 \pm 0.32$ $\mathrm{mm}$ in the study and control groups, respectively. The results suggest that myopic reduction and control would also be achieved for high myopes by using ortho-k and spectacles.

\section{Safety}

Liu et al investigated the safety of ortho-k by reviewing 170 publications. ${ }^{78}$ It was concluded that corneal staining was the most typical complication. Chan et al reported that the incidence and severity of corneal staining increased with ortho-k wear. ${ }^{16}$ When lens binding occurred, central corneal staining was the result. Chan et al suggested to use fenestrated lenses or to ask the patients to instill artificial tears before lens removal in order to minimize the severity of the lens binding. ${ }^{16,79}$ It has been suggested that central corneal staining is common, and practitioners should monitor the patients carefully. 


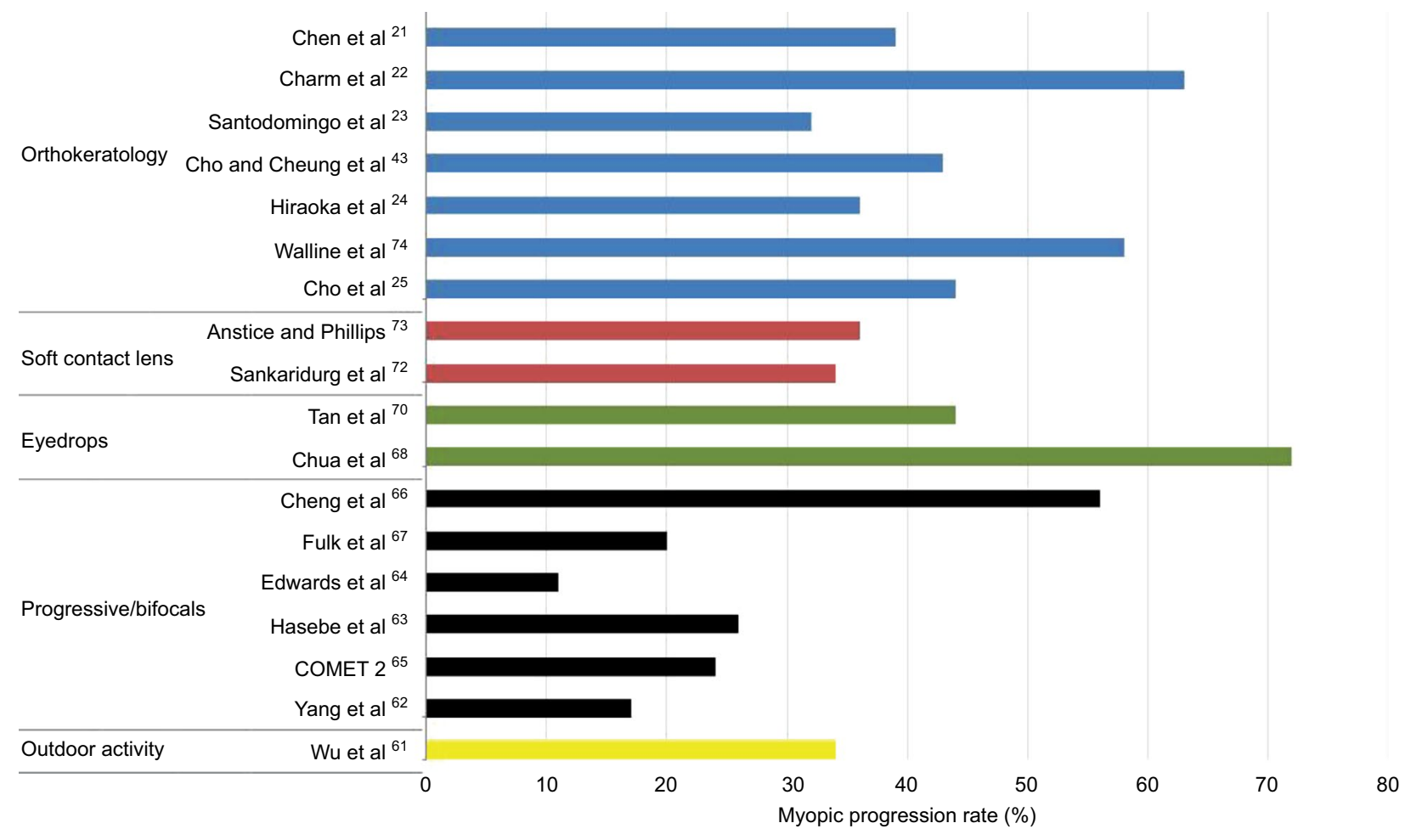

Figure I Myopic progression rates in clinical studies using different interventions.

Some microbial keratitis (MK) cases have been reported with ortho-k treatment. ${ }^{80-82}$ Underlying risk factors include inadequate training of practitioners and wearers, poor lens handling, poor patient compliance, and inadequate follow-up. A recent review indicated a drop in ortho-k-related MK. ${ }^{83}$ Bullimore et al estimated the incidence of MK in children at the rate of 13.9 in 10,000 patients, which is similar to the risk with overnight contact lens wear. ${ }^{84}$ Hence, practitioners should provide clear instructions and regular follow-up to make sure good lens care and compliance in ortho-k treatment to minimize complications. It is also important to provide up-to-date training courses by schools/colleges of optometry worldwide. ${ }^{27}$

Pigmented iron deposits ${ }^{85-87}$ and fibrillary lines ${ }^{88,89}$ have been reported in long-term ortho-k wear. Intensity increased with the continuance of ortho-k wear, but both will disappear after the termination of the treatment.

\section{Patient perspectives}

Ortho-k reshapes the corneal profile and changes the optical quality of the cornea. The higher-order aberrations were increased significantly after ortho-k treatment. ${ }^{90-92}$ Although most studies showed comparable visual acuity in high contrast between pre- and post-ortho-k treatment, contrast sensitivity was reduced. ${ }^{93}$ Common complaints were halos and glare perceived in dim light. Undesired visual anomalies are expected to disappear after the first weeks of treatment, ${ }^{94}$ and it has been hypothesized that the increase in light distortion is a short-term condition that improves when the subject adapts. ${ }^{95}$

Cho et $\mathrm{al}^{77}$ and Chan et $\mathrm{al}^{16}$ conducted interviews with 61 and 94 ortho-k patients, respectively. More than $70 \%{ }^{77}$ and $90 \%{ }^{16}$ of the subjects ranked "good" or "very good" unaided distance vision after lens wear. Those with high baseline myopia reported worsened distance vision toward the end of the day. Hiraoka et al confirmed that patients with higher baseline myopia were likely to report lower levels of satisfaction and that post-ortho-k unaided visual acuity was associated with patient satisfaction. ${ }^{96}$ When the patients did not wear ortho-k every night, the vision quality varied. Patients who wore the lens every night reported higher satisfaction than those who reported skipping at least one night of lens wear. ${ }^{97}$

Santodomingo et al delivered questionnaires to evaluate the satisfactions between ortho-k-wearing and spectaclewearing groups. ${ }^{98}$ Children wearing ortho-k lenses were more satisfied than those wearing spectacles in terms of overall vision, appearance, academic performance, and peer perception. The guardians of children under ortho-k group preferred that they continue wearing ortho-k.

\section{Conclusion}

The ultimate clinical goals were full myopic reduction, good myopic control, and good ocular health. Sufficient evidence 
was found that ortho-k is a clinically safe option for myopic reduction and myopic control. However, center lens fitting (centered topographical response) is only a starting point. Long-term healthy treatment requires combined efforts from practitioners, parents, and children.

\section{Disclosure}

The author reports no conflicts of interest in this work.

\section{References}

1. Kerns RL. Research in orthokeratology. Part I: introduction and background. J Am Optom Assoc. 1976;47(8):1047-1051.

2. Kerns RL. Research in orthokeratology. Part II: experimental design, protocol and method. J Am Optom Assoc. 1976;47(10):1275-1285.

3. Kerns RL. Research in orthokeratology. Part III: results and observations. J Am Optom Assoc. 1976;47(12):1505-1515.

4. Kerns RL. Research in orthokeratology. Part VII: examination of techniques, procedures and control. J Am Optom Assoc. 1977;48(12): 1541-1553.

5. Kerns RL. Research in orthokeratology. Part VI: statistical and clinical analyses. J Am Optom Assoc. 1977;48(9):1134-1147.

6. Kerns RL. Research in orthokeratology. Part V: results and observations-recovery aspects. J Am Optom Assoc. 1977;48(3):345-359.

7. Kerns RL. Research in orthokeratology. Part IV: results and observations. J Am Optom Assoc. 1977;48(2):227-238.

8. Kerns RL. Research in orthokeratology. Part VIII: results, conclusions and discussion of techniques. JAm Optom Assoc. 1978;49(3):308-314.

9. Polse KA. Orthokeratology as a clinical procedure. Am J Optom Physiol Opt. 1977;54(6):345-346.

10. Coon LJ. Orthokeratology: part I historical perspective. J Am Optom Assoc. 1982;53(3):187-195.

11. Efron N. Overnight orthokeratology. Optom Vis Sci. 2000;77(12):627-629.

12. Swarbrick HA. Orthokeratology review and update. Clin Exp Optom. 2006;89(3):124-143.

13. Binder PS, May CH, Grant SC. An evaluation of orthokeratology. Ophthalmology. 1980;87(8):729-744.

14. Lui WO, Edwards MH, Cho P. Contact lenses in myopia reduction from orthofocus to accelerated orthokeratology. Cont Lens Anterior Eye. 2000;23(3):68-76.

15. Nichols JJ, Marsich MM, Nguyen M, Barr JT, Bullimore MA. Overnight orthokeratology. Optom Vis Sci. 2000;77(5):252-259.

16. Chan B, Cho P, Cheung SW. Orthokeratology practice in children in a university clinic in Hong Kong. Clin Exp Optom. 2008;91(5):453-460.

17. Chan B, Cho P, Mountford J. Relationship between corneal topographical changes and subjective myopic reduction in overnight orthokeratology: a retrospective study. Clin Exp Optom. 2010;93(4):237-242.

18. Mountford J, Cho P, Chui WS. Is fluorescein pattern analysis a valid method of assessing the accuracy of reverse geometry lenses for orthokeratology? Clin Exp Optom. 2005;88(1):33-38.

19. Swarbrick HA, Alharbi A, Watt K, Lum E, Kang P. Myopia control during orthokeratology lens wear in children using a novel study design. Ophthalmology. 2015;122(3):620-630.

20. Rajabi MT, Hosseini SS, Ghorbani Z, et al. Utility of orthokeratology contact lenses; efficacy of myopia correction and level of patient satisfaction in Iranian myopic/myope-astigmatic patients. J Curr Ophthalmol. 2015;27(3-4):99-102.

21. Chen C, Cheung SW, Cho P. Myopia control using toric orthokeratology (TO-SEE study). Invest Ophthalmol Vis Sci. 2013;54(10):6510-6517.

22. Charm J, Cho P. High myopia-partial reduction ortho-k: a 2-year randomized study. Optom Vis Sci. 2013;90(6):530-539.

23. Santodomingo-Rubido J, Villa-Collar C, Gilmartin B, Gutierrez-Ortega R. Myopia control with orthokeratology contact lenses in Spain: refractive and biometric changes. Invest Ophthalmol Vis Sci. 2012;53(8):5060-5065.
24. Hiraoka T, Kakita T, Okamoto F, Takahashi H, Oshika T. Long-term effect of overnight orthokeratology on axial length elongation in childhood myopia: a 5-year follow-up study. Invest Ophthalmol Vis Sci. 2012;53(7):3913-3919.

25. Cho P, Cheung SW, Edwards M. The longitudinal orthokeratology research in children (LORIC) in Hong Kong: a pilot study on refractive changes and myopic control. Curr Eye Res. 2005;30(1):71-80.

26. Walline JJ, Rah MJ, Jones LA. The Children's Overnight Orthokeratology Investigation (COOKI) pilot study. Optom Vis Sci. 2004;81(6):407-413.

27. Parker KE, Leach NE. Orthokeratology: an academic perspective. Eye Contact Lens. 2016;42(1):56-60.

28. Cho P, Boost M, Cheng R. Non-compliance and microbial contamination in orthokeratology. Optom Vis Sci. 2009;86(11):1227-1234.

29. Cho P, Cheung SW, Mountford J, White P. Good clinical practice in orthokeratology. Cont Lens Anterior Eye. 2008;31(1):17-28.

30. Mountford J, Pesudovs K. An analysis of the astigmatic changes induced by accelerated orthokeratology. Clin Exp Optom. 2002;85(5):284-293.

31. Cho P, Cheung SW, Edwards MH. Practice of orthokeratology by a group of contact lens practitioners in Hong Kong. Part 2: orthokeratology lenses. Clin Exp Optom. 2003;86(1):42-46.

32. Chen $\mathrm{C}, \mathrm{Cho}$ P. Toric orthokeratology for high myopic and astigmatic subjects for myopic control. Clin Exp Optom. 2012;95(1):103-108.

33. Chen CC, Cheung SW, Cho P. Toric orthokeratology for highly astigmatic children. Optom Vis Sci. 2012;89(6):849-855.

34. Chan B, Cho P, de Vecht A. Toric orthokeratology: a case report. Clin Exp Optom. 2009;92(4):387-391.

35. Cho P, Lam AK, Mountford J, Ng L. The performance of four different corneal topographers on normal human corneas and its impact on orthokeratology lens fitting. Optom Vis Sci. 2002;79(3):175-183.

36. Chui WS, Cho P. A comparative study of the performance of different corneal topographers on children with respect to orthokeratology practice. Optom Vis Sci. 2005;82(5):420-427.

37. Dave T. Corneal topography and its measurement. In: Mountford J, Dave T, Ruston D, editors. Orthokeratology: Principles and Practice. Oxford: Butterworth-Heinemann; 2004: 17-45.

38. Luo M, Ma S, Liang N. Clinical efficacy of toric orthokeratology in myopic adolescent with moderate to high astigmatism. Eye Sci. 2014;29(4):209-213, 218.

39. Paune J, Cardona G, Quevedo L. Toric double tear reservoir contact lens in orthokeratology for astigmatism. Eye Contact Lens. 2012;38(4):245-251.

40. Munnerlyn CR, Koons SJ, Marshall J. Photorefractive keratectomy: a technique for laser refractive surgery. J Cataract Refract Surg. 1988;14(1):46-52.

41. van der Worp E, Ruston D. Orthokeratology: an update. OiP. 2006; 7:47-60.

42. Carney LG. Luminance of fluorescein solutions. Am J Optom Arch Am Acad Optom. 1972;49(3):200-204.

43. Cho P, Cheung SW. Retardation of myopia in orthokeratology (ROMIO) study: a 2-year randomized clinical trial. Invest Ophthalmol Vis Sci. 2012;53(11):7077-7085.

44. Gifford P, Au V, Hon B, Siu A, Xu P, Swarbrick HA. Mechanism for corneal reshaping in hyperopic orthokeratology. Optom Vis Sci. 2009;86(4):e306-e311.

45. Gifford P, Swarbrick HA. Time course of corneal topographic changes in the first week of overnight hyperopic orthokeratology. Optom Vis Sci. 2008;85(12):1165-1171.

46. Li F, Jiang ZX, Hao P, Li X. A meta-analysis of central corneal thickness changes with overnight orthokeratology. Eye Contact Lens. 2016;42(2):141-146.

47. Nieto-Bona A, Gonzalez-Mesa A, Nieto-Bona MP, Villa-Collar C, Lorente-Velazquez A. Short-term effects of overnight orthokeratology on corneal cell morphology and corneal thickness. Cornea. 2011;30(6):646-654.

48. Alharbi A, Swarbrick HA. The effects of overnight orthokeratology lens wear on corneal thickness. Invest Ophthalmol Vis Sci. 2003;44(6):2518-2523. 
49. Gifford P, Alharbi A, Swarbrick HA. Corneal thickness changes in hyperopic orthokeratology measured by optical pachometry. Invest Ophthalmol Vis Sci. 2011;52(6):3648-3653.

50. Mountford J. An analysis of the changes in corneal shape and refractive error induced by accelerated orthokeratology. ICLC. 1997;24(4): $128-144$.

51. Gardiner HK, Leong MA, Gundel RE. Quantifying regression with orthokeratology. Contact Lens Spec. 2005;20:40-43. Available from: http://www.clspectrum.com/articleviewer.aspx?articleID=12892. Accessed December 20, 2016.

52. Cooper J, Schulman E, Jamal N. Current status on the development and treatment of myopia. Optometry. 2012;83(5):179-199.

53. Kang P, Gifford P, McNamara P, Wu J, Yeo S, Vong B, Swarbrick H. Peripheral refraction in different ethnicities. Invest Ophthalmol Vis Sci. 2010;51(11):6059-6065.

54. Tabernero J, Ohlendorf A, Fischer MD, Bruckmann AR, Schiefer U, Schaeffel F. Peripheral refraction profiles in subjects with low foveal refractive errors. Optom Vis Sci. 2011;88(3):E388-E394.

55. Mutti DO, Hayes JR, Mitchell GL, et al. Refractive error, axial length, and relative peripheral refractive error before and after the onset of myopia. Invest Ophthalmol Vis Sci. 2007;48(6):2510-2519.

56. Mutti DO, Sinnott LT, Mitchell GL, et al. Relative peripheral refractive error and the risk of onset and progression of myopia in children. Invest Ophthalmol Vis Sci. 2011;52(1):199-205.

57. Kang P, Swarbrick H. Time course of the effects of orthokeratology on peripheral refraction and corneal topography. Ophthalmic Physiol Opt. 2013;33(3):277-282.

58. Kang P, Swarbrick H. Peripheral refraction in myopic children wearing orthokeratology and gas-permeable lenses. Optom Vis Sci. 2011;88(4):476-482.

59. Queiros A, Gonzalez-Meijome JM, Jorge J, Villa-Collar C, Gutierrez AR. Peripheral refraction in myopic patients after orthokeratology. Optom Vis Sci. 2010;87(5):323-329.

60. Charman WN, Mountford J, Atchison DA, Markwell EL. Peripheral refraction in orthokeratology patients. Optom Vis Sci. 2006;83(9):641-648.

61. Wu PC, Tsai CL, Wu HL, Yang YH, Kuo HK. Outdoor activity during class recess reduces myopia onset and progression in school children. Ophthalmology. 2013;120(5):1080-1085.

62. Yang Z, Lan W, Ge J, et al. The effectiveness of progressive addition lenses on the progression of myopia in Chinese children. Ophthalmic Physiol Opt. 2009;29(1):41-48.

63. Hasebe S, Ohtsuki H, Nonaka T, et al. Effect of progressive addition lenses on myopia progression in Japanese children: a prospective, randomized, double-masked, crossover trial. Invest Ophthalmol Vis Sci. 2008;49(7):2781-2789.

64. Edwards MH, Li RW, Lam CS, Lew JK, Yu BS. The Hong Kong progressive lens myopia control study: study design and main findings. Invest Ophthalmol Vis Sci. 2002;43(9):2852-2858.

65. Correction of Myopia Evaluation Trial 2 Study Group for the Pediatric Eye Disease Investigator Group. Progressive-addition lenses versus single-vision lenses for slowing progression of myopia in children with high accommodative lag and near esophoria. Invest Ophthalmol Vis Sci. 2011;52(5):2749-2757.

66. Cheng D, Schmid KL, Woo GC, Drobe B. Randomized trial of effect of bifocal and prismatic bifocal spectacles on myopic progression: two-year results. Arch Ophthalmol. 2010;128(1):12-19.

67. Fulk GW, Cyert LA, Parker DE. A randomized trial of the effect of single-vision vs. bifocal lenses on myopia progression in children with esophoria. Optom Vis Sci. 2000;77(8):395-401.

68. Chua WH, Balakrishnan V, Chan YH, et al. Atropine for the treatment of childhood myopia. Ophthalmology. 2006;113(12):2285-2291.

69. Chia A, Chua WH, Cheung YB, et al. Atropine for the treatment of childhood myopia: safety and efficacy of $0.5 \%, 0.1 \%$, and $0.01 \%$ doses (atropine for the treatment of myopia 2). Ophthalmology. 2012; $119(2): 347-354$
70. Tan DT, Lam DS, Chua WH, Shu-Ping DF, Crockett RS; Asian Pirenzepine Study Group. One-year multicenter, double-masked, placebo-controlled, parallel safety and efficacy study of $2 \%$ pirenzepine ophthalmic gel in children with myopia. Ophthalmology. 2005;112(1):84-91.

71. Sankaridurg P, Donovan L, Varnas S, et al. Spectacle lenses designed to reduce progression of myopia: 12-month results. Optom Vis Sci. 2010; 87(9):631-641.

72. Sankaridurg P, Holden B, Smith E 3rd, et al. Decrease in rate of myopia progression with a contact lens designed to reduce relative peripheral hyperopia: one-year results. Invest Ophthalmol Vis Sci. 2011;52(13): 9362-9367.

73. Anstice NS, Phillips JR. Effect of dual-focus soft contact lens wear on axial myopia progression in children. Ophthalmology. 2011;118(6): 1152-1161.

74. Walline JJ, Jones LA, Sinnott LT. Corneal reshaping and myopia progression. Br J Ophthalmol. 2009;93(9):1181-1185.

75. Kakita T, Hiraoka T, Oshika T. Influence of overnight orthokeratology on axial elongation in childhood myopia. Invest Ophthalmol Vis Sci. 2011;52(5):2170-2174.

76. Oguri A, Nishimura M. Advanced orthokeratology for Japanese patients with high myopia. Invest Ophthalmol Vis Sci. 2003;44(13):3290.

77. Cho P, Cheung SW, Edwards MH, Fung J. An assessment of consecutively presenting orthokeratology patients in a Hong Kong based private practice. Clin Exp Optom. 2003;86(5):331-338.

78. Liu YM, Xie P. The safety of orthokeratology-a systematic review. Eye Contact Lens. 2016;42(1):35-42.

79. Cheung SW, Cho P. Subjective and objective assessments of the effect of orthokeratology-a cross-sectional study. Curr Eye Res. 2004;28(2):121-127.

80. Watt K, Swarbrick HA. Microbial keratitis in overnight orthokeratology: review of the first 50 cases. Eye Contact Lens. 2005;31(5):201-208.

81. Watt KG, Boneham GC, Swarbrick HA. Microbial keratitis in orthokeratology: the Australian experience. Clin Exp Optom. 2007;90(3):182187; quiz 188-189.

82. Van Meter WS, Musch DC, Jacobs DS, Kaufman SC, Reinhart WJ, Udell IJ; American Academy of Ophthalmology. Safety of overnight orthokeratology for myopia: a report by the American Academy of Ophthalmology. Ophthalmology. 2008;115(12):2301-2313.e1.

83. Song X, Xu L, Sun S, Zhao J, Xie L. Pediatric microbial keratitis: a tertiary hospital study. Eur J Ophthalmol. 2012;22(2):136-141.

84. Bullimore MA, Sinnott LT, Jones-Jordan LA. The risk of microbial keratitis with overnight corneal reshaping lenses. Optom Vis Sci. 2013;90(9):937-944.

85. Gonzalez-Meijome JM, Gonzalez-Perez J, Garcia-Porta N, Diaz-Rey A, Parafita-Mato MA. Pigmented corneal ring associated with orthokeratology in Caucasians: case reports. Clin Exp Optom. 2012;95(5): 548-552.

86. Cho P, Chui WS, Cheung SW. Reversibility of corneal pigmented arc associated with orthokeratology. Optom Vis Sci. 2003;80(12):791-795

87. Cheung SW, Cho P, Cheung A. White lesion in the corneal pigmented ring associated with orthokeratology. Ophthalmic Physiol Opt. $2005 ; 25(3): 264-268$.

88. Lum E, Swarbrick H. Fibrillary lines in overnight orthokeratology. Clin Exp Optom. 2007;90(4):299-302.

89. Cheung SW, Cho P, Bron AJ, Chui V, Chan B. Case report: the occurrence of fibrillary lines in overnight orthokeratology. Ophthalmic Physiol Opt. 2006;26(5):525-531.

90. Mao XJ, Lu F, Qu J. [Effects after orthokeratology on corneal topography and monochromic wavefront aberration]. Zhonghua Yan Ke Za Zhi. 2004;40(7):471-473. Chinese.

91. Hiraoka T, Okamoto C, Ishii Y, Kakita T, Oshika T. Contrast sensitivity function and ocular higher-order aberrations following overnight orthokeratology. Invest Ophthalmol Vis Sci. 2007;48(2):550-556.

92. Hiraoka T, Okamoto C, Ishii Y, Takahira T, Kakita T, Oshika T. Mesopic contrast sensitivity and ocular higher-order aberrations after overnight orthokeratology. Am J Ophthalmol. 2008;145(4):645-655. 
93. Hiraoka T, Okamoto C, Ishii Y, Kakita T, Okamoto F, Oshika T. Time course of changes in ocular higher-order aberrations and contrast sensitivity after overnight orthokeratology. Invest Ophthalmol Vis Sci. 2008;49(10):4314-4320.

94. Stillitano I, Schor P, Lipener C, Hofling-Lima AL. Long-term follow-up of orthokeratology corneal reshaping using wavefront aberrometry and contrast sensitivity. Eye Contact Lens. 2008;34(3):140-145.

95. Santolaria SanzE, Cervino A, Queiros A, Villa-Collar C, Lopes-Ferreira D, Gonzalez-Meijome JM. Short-term changes in light distortion in orthokeratology subjects. Biomed Res Int. 2015;2015:278425.
96. Hiraoka T, Okamoto C, Ishii Y, et al. Patient satisfaction and clinical outcomes after overnight orthokeratology. Optom Vis Sci. 2009;86(7):875-882.

97. Santolaria E, Cervino A, Queiros A, Brautaset R, Gonzalez-Meijome JM. Subjective satisfaction in long-term orthokeratology patients. Eye Contact Lens. 2013;39(6):388-393.

98. Santodomingo-Rubido J, Villa-Collar C, Gilmartin B, Gutierrez-Ortega R. Myopia control with orthokeratology contact lenses in Spain: a comparison of vision-related quality-of-life measures between orthokeratology contact lenses and single-vision spectacles. Eye Contact Lens. 2013;39(2):153-157.

\section{Publish your work in this journal}

Clinical Optometry is an international, peer-reviewed, open access journa publishing original research, basic science, clinical and epidemiological studies, reviews and evaluations on clinical optometry. All aspects of patient care are addressed within the journal as well as the practice of optometry including economic and business analyses. Basic and clinical

Submit your manuscript here: https://www.dovepress.com/clinical-optometry-journa
Dovepress

research papers are published that cover all aspects of optics, refraction and its application to the theory and practice of optometry. The manuscrip management system is completely online and includes a very quick and fair peer-review system, which is all easy to use. Visit http://www.dovepress. com/testimonials.php to read real quotes from published authors. 